\title{
Flow Characteristics in Weft-Acceleration Pipe of Air-Jet Loom
}

\author{
Effect of Forced Flow through Weft-Guide Pipe of Main Nozzle
}

By Sadasuke Fukai, Member, TMSJ

Faculty of Engineering, Osaka City University, Osaka, Japan

Based on the Journal of the Textile Machinery Society of Japan, Transactions, Vol.46, No.2, T42-T49 (1993-2)

\begin{abstract}
This paper describes the experimental study concerning air-flow characteristics in the weft-acceleration pipe of an air-jet loom when forced flow is given to the weft-guide pipe of the nozzle trially made. Central flow through the weft-guide pipe is composed of both flow naturally sucked by the pressurized annular flow, and positively gushed-inflow (forced flow). To study the flow condition useful for acceleration and flight of a weft, the flow in the weft-acceleration pipe was measured with a hot-wire anemometer when $M$ was changed stepwise, where $M$ is the ratio of flow rate of the central flow to that of the annular flow through the nozzle. During the experiments, $R$, the ratio of the annular-exit area to the central-exit area and $R e$, Reynolds number of air flow in the weft-acceleration pipe, were kept constant $(R=0.343, R e=$ $1.7 \times 10^{4}$ ).

The following results were obtained : When $M$ is increased : (1) velocity defect along the axis of the weft-acceleration pipe is reduced. (2) turbulence in that pipe is weakened.

As a result, it is sure that a flow useful for acceleration and flight of the weft is generated. This fact can also explain the reason why the modern tandem main nozzle can achieve steady flight of weft.
\end{abstract}

\section{Introduction}

Weft insertion for an air-jet loom (AJL) is operated at high-insertion rate, and air capacity required for that insertion depends significantly on characteristics of weft yarns. To minimize the air consumption, the insertion unit has to be adjusted most suitably for the characteristics of wefts during weft insertion.

Recently, many researchers have studied the weftinsertion unit of the AJL. A. Wahhoud[1] and J. Lunenschloss $^{[2][3]}$ studied weft-flight time, velocity and acceleration to know possibility and limit of the insertion. They measured weft-insertion time and observed weftflight behavior. K. Yoshida et al. ${ }^{[4]}$ pointed out that weft-insertion condition depends on nozzle pressure, weftinsertion length, loom speed, kinds of yarns and weft accumulators. They used 2 main nozzles arranged in a line with a space to check overall behavior of the weft with a laser Doppler velocimeter. However, we can scarcely find any research concerning flow characteristics in the main nozzle. Only a few researches we can find are ; Experimental analysis on yarn tension in the main nozzle of the AJL by N. Iwaki et al. ${ }^{[5]}$; Study on flow in a doublecoaxial pipe consisting of annular flow and central flow sucked naturally by annular flow by $T$. Kiwata et al. ${ }^{[6][7]}$; Analysis on variation of velocity of one-dimensional compressible flow through the main nozzle of the AJL with a modified reed and auxiliary nozzle by $\mathrm{M}$. Isida et al. ${ }^{[8]}$.

Weft-flight behavior is remarkably affected by air jets from auxiliary nozzles and shapes of air guides. However, flow condition in the weft-acceleration pipe, which accelerates weft initially, is so important that it can not be neglected. Hitherto, the central flow (flow through the weft-guide pipe) was induced only by the annular flow. But nowadays, the main nozzle of two stage tandem is widely used which gives forced flow through the weftguide pipe to improve stability of weft flight. Moreover, three stage tandem nozzle can be found in super high speed $\mathrm{AJL}^{[9]}$. However, no study on flow in the weftacceleration pipe of those multiple stage tandem nozzles can be found.

This paper describes the experimental study on confined flow through the weft-acceleration pipe to obtain effectively accelerated weft flight by using forced central flow in the weft-guide pipe. The flow was measured with a hot-wire anemometer with changing the ratio between the central flow rate and the annular flow rate.

The notations used in this paper are as follows : $D$ : Inner diameter of weft-acceleration pipe ... [m] $k$ : Turbulence energy .......... [J $\left./ \mathrm{m}^{3}\right]$

$M$ : Flow-rate ratio (central flow rate / annular flow rate)

$R$ : Area ratio of nozzle (annular exit area / central exit area $=0.343$, constant)

$R e$ : Reynolds number of flow in weft-acceleration pipe (=D $\bar{U}_{m} / \nu=1.7 \times 10^{4}$, constant)

$\bar{U}:$ Mean axial velocity .......... [m/s]

$\bar{U}_{c}$ : Mean axial velocity along the pipe axis ... [m/s]

$\bar{U}_{m}$ : Mean axial velocity in a section of the pipe . [m/s]

$u$, v: Fluctuating velocities, axial and radial ... [m/s]

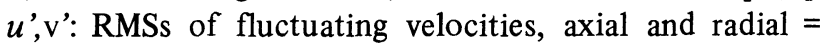

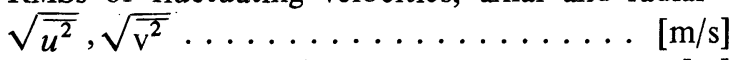

$x$ : Axial distance from the nozzle exit ..... [m]

$y$ : Radial distance from the pipe center ..... [m]

$\nu$ : kinematic viscosity of air $\ldots \ldots \ldots \ldots\left[\mathrm{m}^{2} / \mathrm{s}\right]$

$\rho:$ Air density $\ldots \ldots \ldots \ldots \ldots \ldots\left[\mathrm{kg} / \mathrm{m}^{3}\right]$

$-\rho \overline{u_{\mathrm{v}}}:$ Reynolds stress $\ldots \ldots \ldots \ldots[\mathrm{Pa}]$ 


\section{Experimental Setup and Method}

Schematic diagram of the experimental setup used is shown in Fig.1. Air was compressed by an air compressor (1). Oil contained in air was eliminated by an air filter (2). After air was cooled with water going through a water cooler (3), it was kept in an air tank (4) to dampen air pulsation. Piping system supplying compressed air to a model main nozzle (10) consisted of two separate pipes arranged from the air tank (4); one for central flow and the other for annular flow. Both lines had mist separators (5) and micro-separators (6) respectively to remove impurities from air. After passing through each pressure reducing valves (7), purified air was supplied to the model main nozzle via two separate pipes as mentioned above.

In experiments, the flow rate (joined flow rate of central flow and annular flow) in a weft-acceleration pipe (9) was kept constant $\left(8.6 \times 10^{-3} \mathrm{~kg} / \mathrm{s}\right.$ at $\left.R e \fallingdotseq 1.7 \times 10^{4}\right)$, but $M$, the flow-rate ratio of the nozzle (central flow rate /annular flow rate), was changed in 4-steps of 1.0, 0.76, 0.41 and 0.09 by regulating each pressure-reducing valve separately. When a weft-guide pipe (8) (30 $\mathrm{mm}$ in inner diameter and $1,800 \mathrm{~mm}$ in length) was opened to the atmosphere at its upstream end and compressed air was supplied only to the annular exit of the nozzle, the central flow through the weft-guide pipe was sucked naturally due to the negative pressure caused by the annular flow. This was the case when $M$ was 0.09 .

Figure 2 shows the model-main nozzle in detail. Concerning the nozzle axis, the position of the weft-

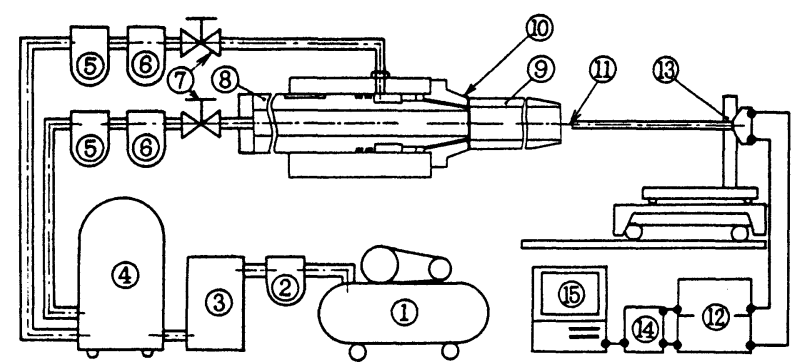
(1): Air Compressor
(2): Air Filter
(3): Water Cooler
(4): Air Tank
(5), (6) : Air Filter
(7): Pressure-Reducing Valve
(8): Weft-Guide Pipe

(9): Weft-Accerelation Pipe
(10): Nozzle
(11): Hot-Wire Probe
(12): Hot-Wire Anemometer
(13): Probe Carriage
(14): A/D Converter
(15): Personal Computer

Fig. 1 Schematic diagram of experimental setup

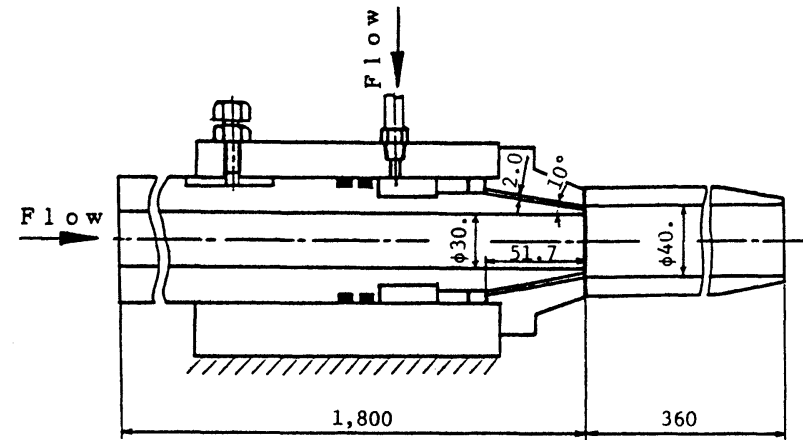

Fig. 2 Detailed view of the model nozzle

acceleration-pipe entrance and that of the nozzle exit were made to coincide with each other. The area ratio of the nozzle, $R$ (annular exit area / central exit area), was kept at a constant value of 0.343 . The weft-acceleration pipe (9) (40 $\mathrm{mm}$ in inner diameter and $360 \mathrm{~mm}$ in length) was set coaxially with the nozzle (10). The weft-guide pipe, the main nozzle, and the weft-acceleration pipe were made of brass, and their flow surfaces were finished smoothly. This model nozzle was not similar to the actually used nozzles, and the area ratio $R$ was a very small constant value. This was because such tests were intended at first as the peculiar flow in the weft-acceleration pipe under extreme condition.

Flow rate of the central flow was measured with a Pitot tube at a weft-guide-pipe center, 1,050 mm downstream from the entrance of the pipe. In the measuring section, fully developed turbulent velocity distribution was established. Flow rate through the weft-acceleration pipe was obtained by measuring the axial velocity of flow at the exit of the pipe.

To know flow condition in the weft-acceleration pipe, the following instruments were used ; a constanttemperature-type hot-wire anemometer (12) (2-channel standard system 7213 made by KANOMAX) and a X-type hot-wire probe (11) using tungusten wire of $5 \mu \mathrm{m}$ in diameter and $2 \mathrm{~mm}$ in length (sensor length of $1 \mathrm{~mm}$, Model 0252R-T5). To measure flow velocity near the pipe wall, a single-sensor probe for upstream side (Model 0248R-T5) was used. The hot-wire probe was inserted into the pipe from downstream and was moved along the radius of each measuring section by the help of a modified reading microscope (13). Fig.3 and Table 1 show the places of measuring sections and points up to 26 sections, $S_{1}$ to $S_{26}$. In each section, mean velocity and fluctuating velocity in axial- and radial directions were measured at 21 points with the $\mathrm{X}$ probe. With the single-sensor hot-wire probe, non-directional mean flow velocity and fluctuating veloci-
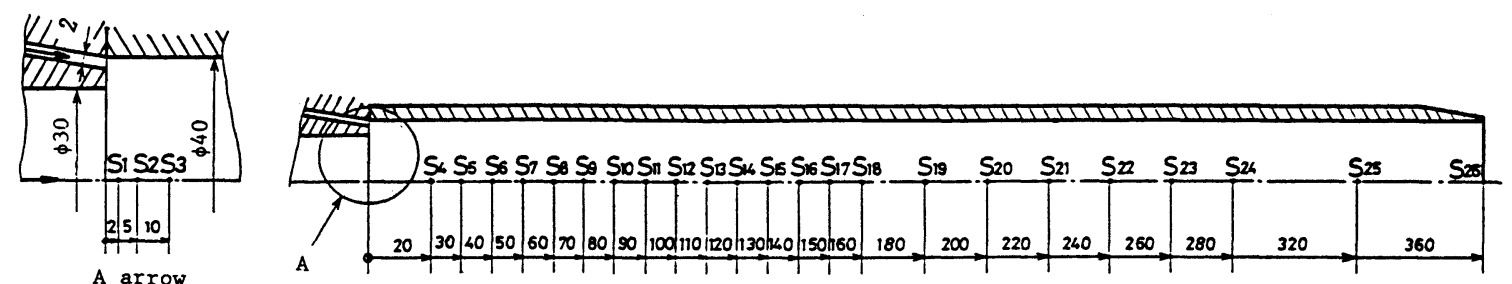

Fig. 3 Measured sections vertical to pipe axis and their symbols 
Table 1 Radial locations of measurements in each section in $\mathrm{mm}$ from pipe center

\begin{tabular}{|c|c|c|c|c|c|c|c|c|c|c|c|c|c|c|c|c|c|c|c|c|c|c|c|c|c|}
\hline Sect ion & \multicolumn{19}{|c|}{ Measuring range with $X$ probe } & 20 & 21 & \multicolumn{4}{|c|}{$\begin{array}{l}\text { Measuring range with } \\
\text { a single wire probe }\end{array}$} \\
\hline$S_{1} \sim S_{4}$ & 0 & 2.0 & 4.0 & 6.0 & 8.0 & 9.0 & 10.0 & 11.0 & 12.0 & 12.5 & 13.0 & 13.5 & 14.0 & 14.5 & 15.0 & 15.5 & 16.0 & 16.5 & 17.0 & 17.5 & 18.0 & 18.4 & 18.8 & 19.2 & 19.6 \\
\hline$S_{8}, \quad S_{6}$ & 0 & 2.0 & 4. 0 & 5.0 & 60 & 7.0 & 8.0 & 8.0 & 10.0 & 11.0 & 12.0 & 13.0 & 14.0 & 14.5 & 15.0 & 15.5 & 16.0 & 16.5 & 17.0 & 17.5 & 18.0 & 18.4 & 18.8 & 18.2 & 19.6 \\
\hline
\end{tabular}

ty were measured at 6 points (see the right side of Table 1). Flow velocity was measured with the hot-wire anemometer, and 3,000 data were sampled with a time interval of $20 \mu \mathrm{s}$ through a fast A/D converter (14), which could sample 2 channel data simultaneously. The data were then processed with a personal computer (15). The static wall pressure of the pipe along its axis was measured at the same time by a Göttingen-type manometer connected with the measurement holes of the pipe wall.

\section{Results and Discussion}

\subsection{Mean-flow velocity and static wall pressure}

Figures $4(a)$ and $4(\mathrm{~b})$ show mean velocity vector distributions of sections $\left(S_{1}\right.$ to $\left.S_{26}\right)$ with the flow-rate ratios of the nozzle, $M$. The vertical axis shows non-dimensional $y / D$, where $y$ is a radial distance from the pipe center and $D$ is the inner diameter of the pipe. The horizontal axis shows non-dimensional $x / D$, where $x$ is the axial distance of the section from the exit of the nozzle. Usually, a vector is shown with an arrow, but in Fig.4 is indicated without an arrow to avoid confusion. Figs.5(a) to 5(d)
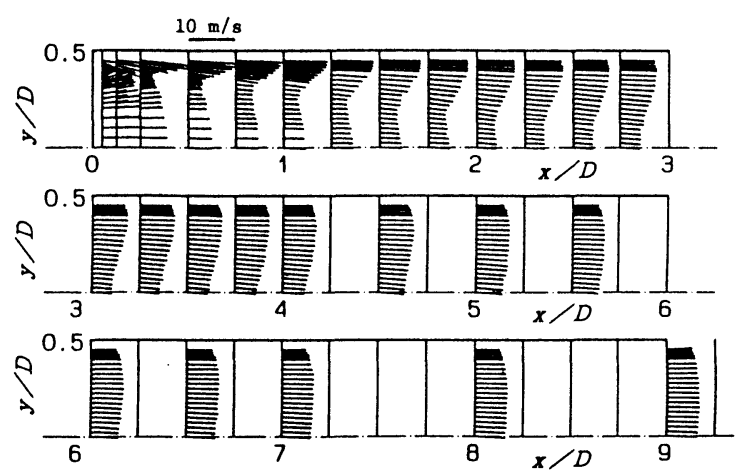

(a) $M=1.00$
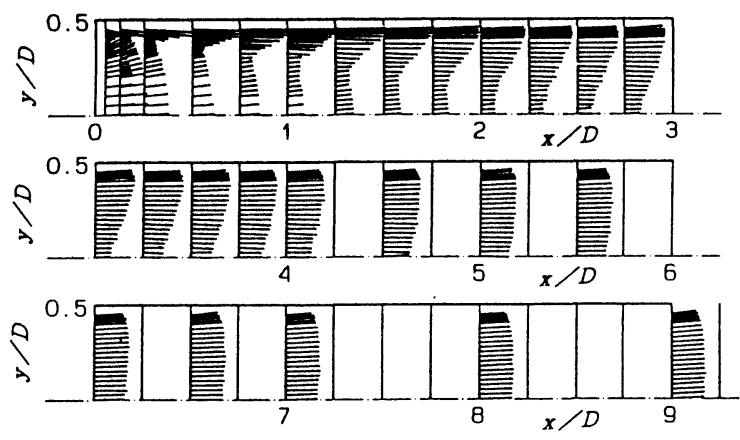

(b) $M=0.76$ show magnified drawings in sections $S_{1}$ to $S_{3}$ with arrows to show the intersection. For all values of $M$, drawings show the remarkable tilt of the central flow toward the pipe wall immediately after the nozzle exit. This is caused by mixing the central flow with the annular flow. Especially, when $M$ is 0.09 , the central flow is induced only by the negative pressure caused by the annular flow. The annular velocity vectors around the nozzle exit are bigger, and the gradients of velocity distributions are steeper than those in other sections. Compared with other $M$ 's, the annular flow in this case tends to be biased towards the pipe wall with $M=0.09$, resulting in delay of mixing the annular flow with the central flow. The point of the minimum-velocity vector moves toward the pipe axis when the section is taken from upstream to downstream. However, downstream from $x / D=6$, the vector distributions in sections become almost the same even if $M$ is different. In Fig.5, velocity vectors near the nozzle tip are very small, and tilt remarkably. This may be because the wall of the nozzle tip brings forth the annular dead water region.

The relationship between $\bar{U}_{c} / \bar{U}_{m}$ and $x / D$ is shown in
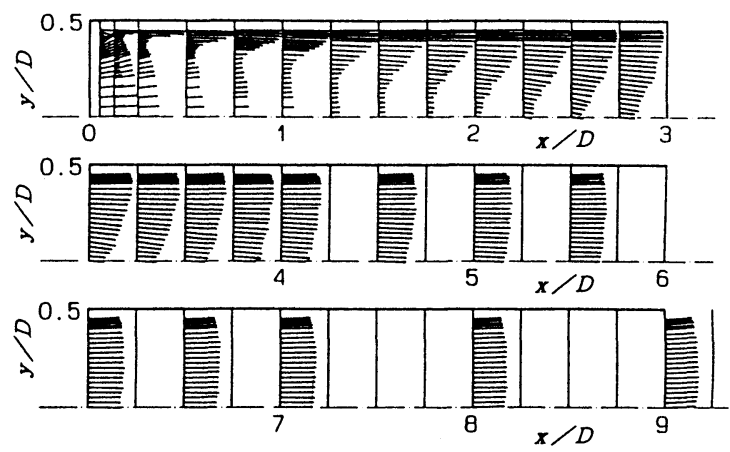

(c) $M=0.41$
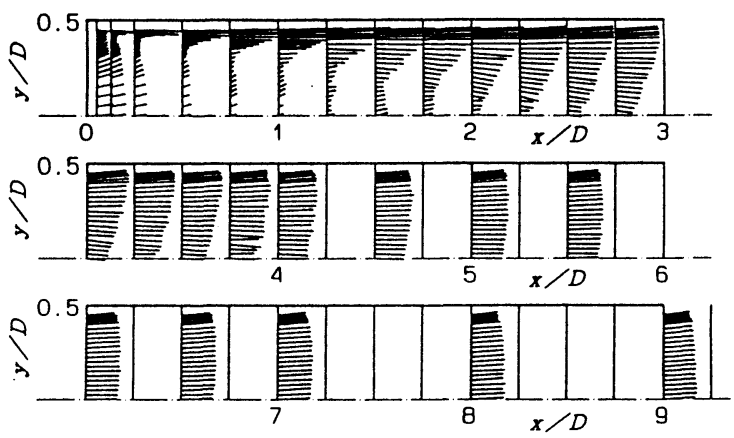

(d) $M=0.09$

Fig. 4 Sectional mean velocity vectors with various flow rate ratio 

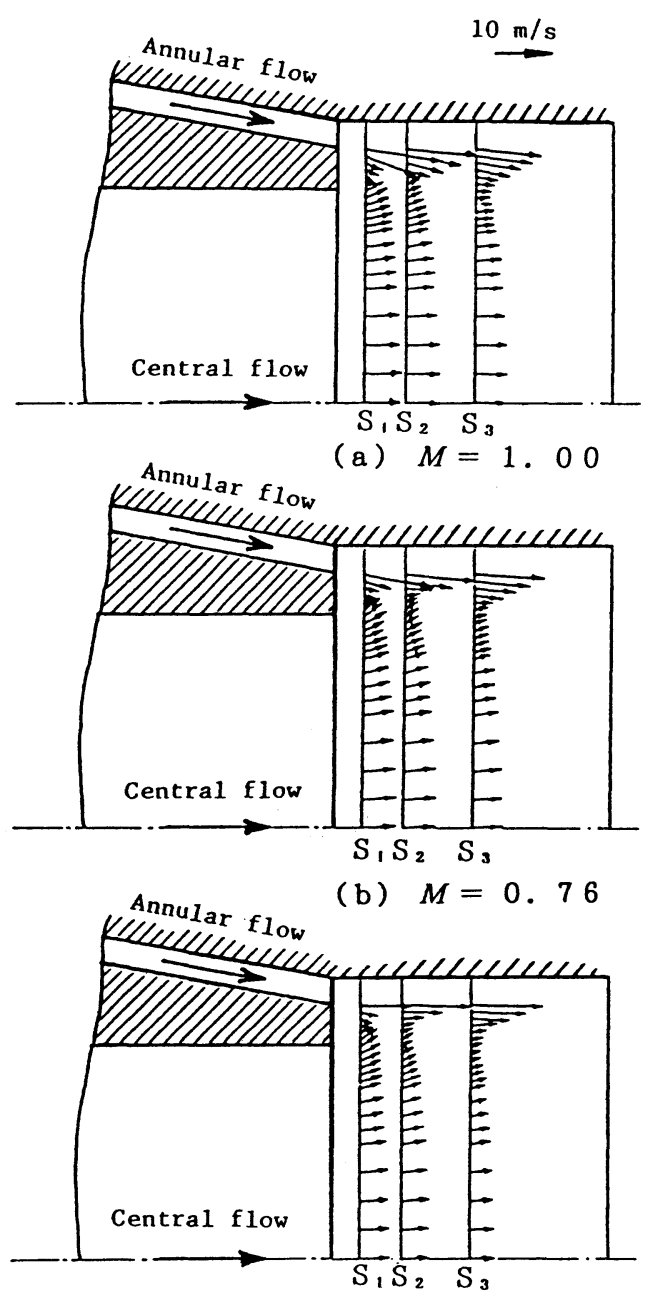

(c) $M=0.41$

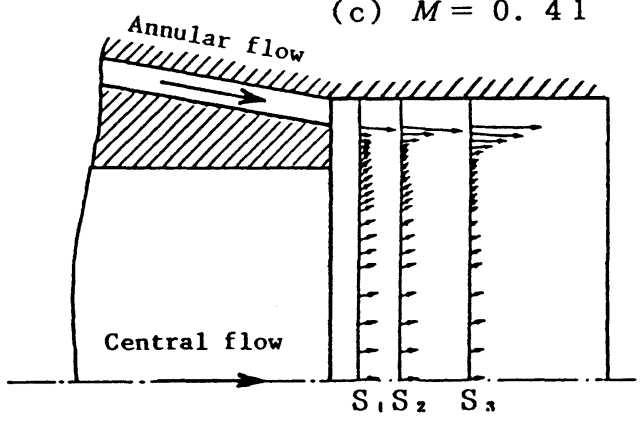

(d) $M=0.09$

Fig. 5 Detailed-mean velocity vectors in $S_{1} \sim S_{3}$

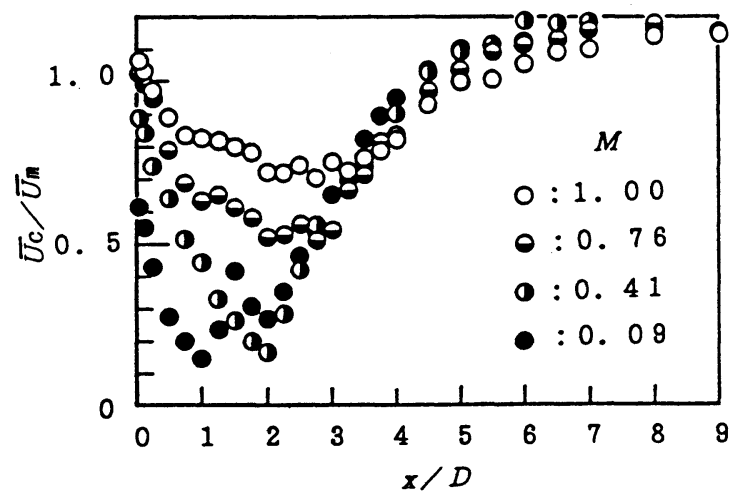

Fig. 6 Mean-axial velocity at the pipe center
Fig.6, where $\overline{U_{c}}$ is the mean axial velocity along the pipe axis and $\bar{U}_{m}$ the mean axial velocity in the pipe section. $\bar{U}_{c} / \bar{U}_{m}$ decreases rapidly from the nozzle exit toward downstream. Such velocity defect along the pipe axis increases with decreasing $M$, and the position of the maximum velocity defect moves towards upstream. When $M$ is $0.09, \bar{U}_{c} / \bar{U}_{m}$ decreases remarkably, and the ratio shows two minimum values between $x / D=1.0$ and 2.0. When $M$ is $1.00, \bar{U}_{c} / \bar{U}_{m}$ decreases rapidly near the nozzle exit, and reduces slowly toward downstream to show the minimum when $x / D$ is 2.75 . However, downstream from $x / D=4.0$, all $\bar{U}_{c} / \bar{U}_{m} s$ show almost the same values irrespective of $M$, and increase slowly.

Figure 7 shows static pressure distributions on the wall. The vertical axis shows $\Delta P$, differential pressure between the wall pressure and the atmospheric pressure. The horizontal axis shows $x / D$. The distributions show steep drop and rise very near the nozzle exit. It is thought that this is caused by the flow separation occurring at the entrance corner of the weft-acceleration pipe (straightcircular pipe) when the annular flow is discharged into the pipe at an angle of $10^{\circ}$ to the pipe axis.

Downstream from $x / D=6$, all wall-pressure distributions go down slowly with nearly the same gradient regardless of the values of $M$. Any pressure drop seems not found during the mixing process of the central flow with the annular flow. It is considered that the pressure gradient becomes constant only when the fluid mixing is nearly finished and the axial velocity distributions are nearly uniform. Sharp drop and rise of the wall pressure near the nozzle exit is observed with every $M$. But when $M=0.09$, the wall pressure drops and rises again between $x=1$ and 2. This region coincides with that where $\bar{U}_{c} / \bar{U}_{m}$ shows two minimum values in Fig.6. So, it is considered that the flow separates from the pipe wall near the nozzle exit, and reattaches. The recirculation zone $\mathrm{e}^{[10][11]}$ is generated between $x / D=1$ and 2 .

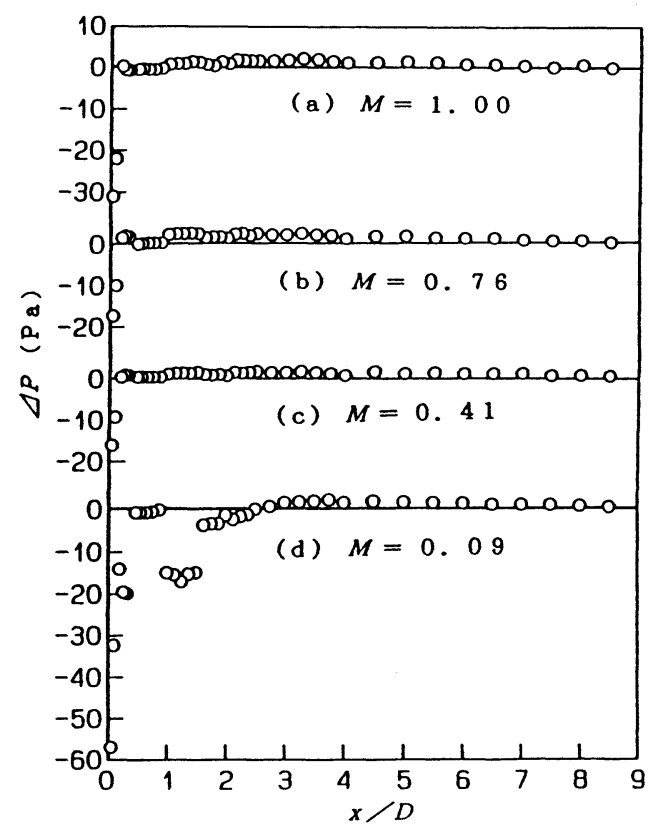

Fig. 7 Wall pressure distributions 


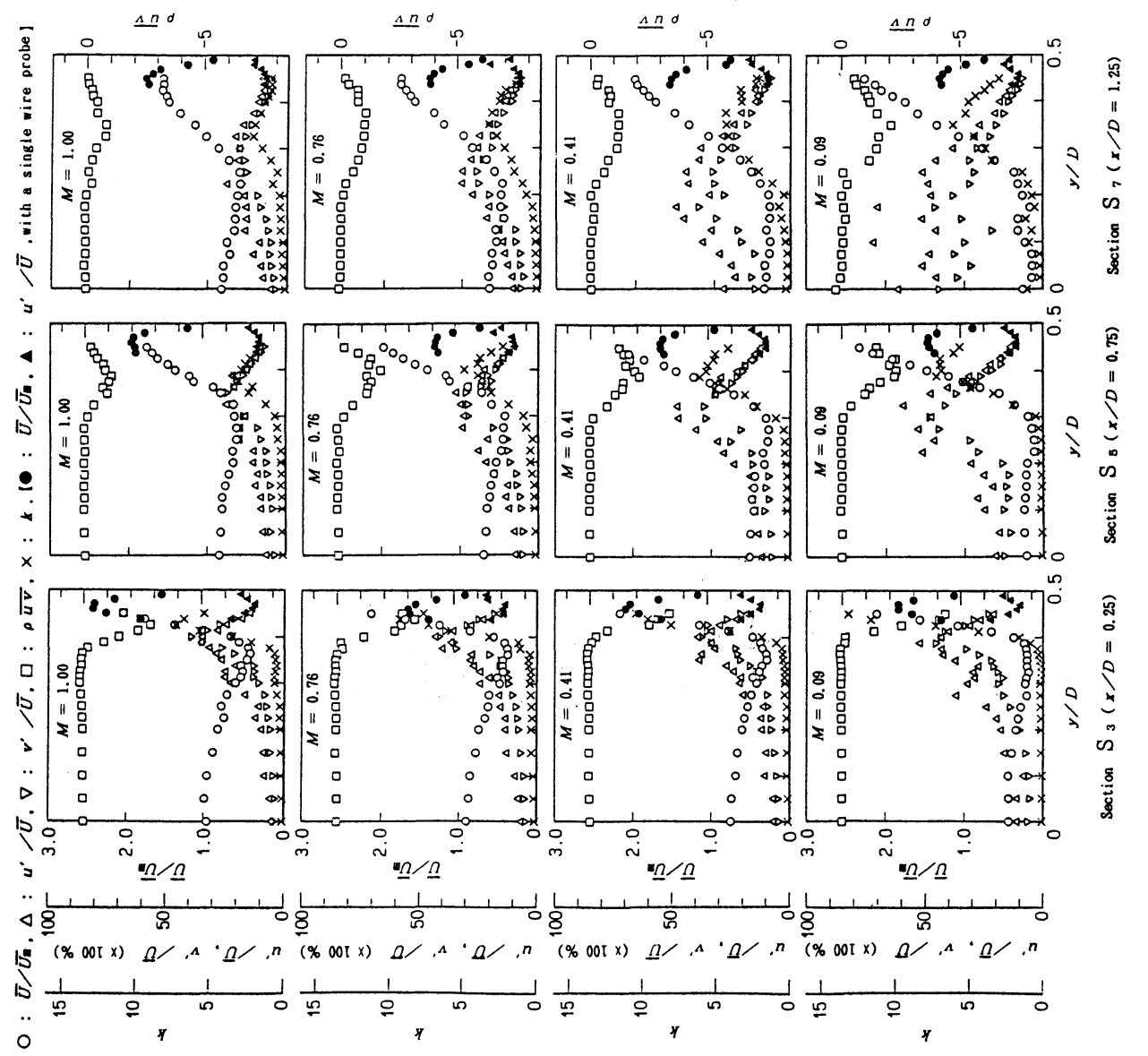

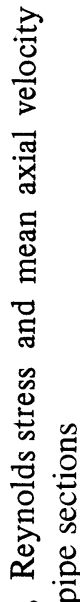

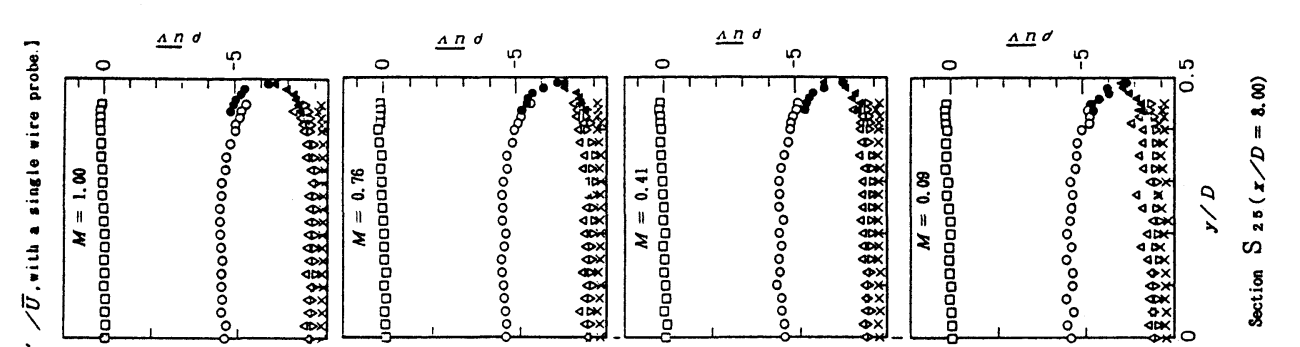

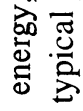
范 营 兽 要 苞草
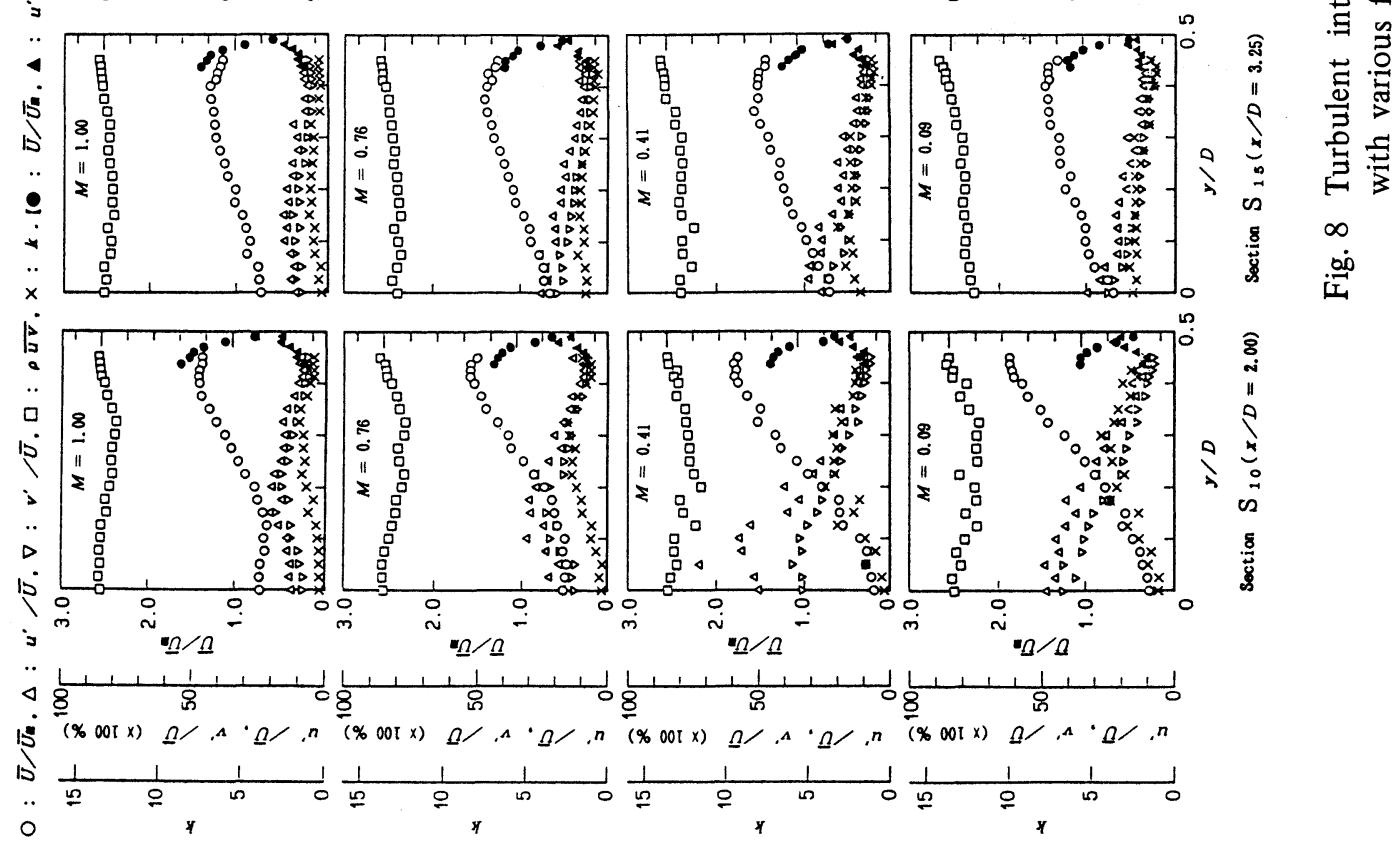


\subsection{Characteristics of turbulence}

Figures 8(a) and (b) show the results of the measurement on flow turbulence in the weft-acceleration pipe. The vertical axes show those values of turbulence energy $k$, turbulence intensities $u^{\prime} / \bar{U}$ and $\mathrm{v}^{\prime} / \bar{U}$, Reynolds stress $(-\rho \overline{u v})$, and mean-axial velocity $\bar{U} / \bar{U}_{m}$. Horizontal axes show non-dimensional ratio of the radial distance to the pipe diameter $y / D$. In Fig.8, data of 6 representative sections $\left(\mathrm{S}_{3}, \mathrm{~S}_{5}, \mathrm{~S}_{7}, \mathrm{~S}_{10}, \mathrm{~S}_{13}\right.$ and $\left.\mathrm{S}_{25}\right)$ are shown according to various values of $M$. As the turbulence component in the pipe-circumferencial direction was not measured at the same time, equation $k=3\left(u^{2}+v^{, 2}\right) / 4$ is used ${ }^{[12]}$ for turbulence energy as it is nearly equivalent to turbulence energy. Also, the axis indicating $(-p \overline{u v})$ is shown in the reverse sign for the convenience.

As shown in Fig.8, both the $k$ distributions and the $(-\rho \overline{u v})$ distributions have almost the same trend. They show the maximum values when velocity distributions show the maximum gradients. When $M$ is smaller, $k$ and $(-\rho \overrightarrow{u v})$ become larger. At all flow-rate ratios, $k$ and $(-\rho \overrightarrow{u v})$ distributions are not flat from section $S_{3}$ to $S_{15}$ $(x / D \leqq 3.25)$. When the values of $k$ and $(-\rho \overline{u v})$ distributions at $M=0.09$ are compared with those at $M=1.00$ on sections from $S_{5}$ to $S_{10}$, the formers are nearly twice as large as the latters. It shows that when $M$ is small there are larger turbulence and steep velocity distribution caused by strong mixing of annular flow with central flow.

Axial turbulence intensity $u^{\prime} / \bar{U}$ is a little stronger than radial turbulence intensity $v^{\prime} / \bar{U}$ as shown in Fig.8 throughout the pipe. When $M$ becomes small, the maximum turbulence intensity grows larger, turbulence area wider, and variation of turbulence intensity stronger. Moreover, damping of turbulence delays toward downstream when $M$ becomes smaller.

In the final section $\mathrm{S}_{25}, u^{\prime} / \bar{U}, \mathrm{v}^{\prime} / \bar{U}$ and $k$ are nearly constant as usually seen in the fully developed turbulent flow through the pipe. Moreover, $\rho \overline{u v}$ is nearly equal to zero. Turbulent component of non-directional velocity increases rapidly toward the pipe wall. The mean axial velocity distributions become uniform.

Back flow in the pipe can be considered in view of the following: (1) The non-directional velocity distributions shown in Fig. 8 have large discontinuity with the mean axial velocity distributions and are remarkably low. (2) There is the axial variation of wall pressure as shown in Fig.7. When $M$ is 0.09 , the recirculation zone may be generated near the pipe wall in the range $x / D \geqq 1$. With other values of $M$ (except $M=1.00$ ), in some pipe sections non-directional velocities are remarkably lower than mean axial velocities, and velocity distributions are highly discontinuous, with circulation regenerated the zone of which seems wider when $M$ becomes smaller.

\section{Conclusion}

The results obtained are summarized as follows :

(1) When the central flow is naturally sucked, the mean axial velocity distributions in pipe sections have high-velocity vectors very near the pipe wall, that is, biased along the pipe wall. Due to this biased flow, the dent of the velocity distribution increases along the pipe axis. When $M$, the flow-rate ratio of the nozzle decreases, the section where $\bar{U}_{c} / \bar{U}_{m}$ is the minimum moves upstream and the value $\bar{U}_{c} / \bar{U}_{m}$ decreases. Particularly, when the central flow is naturally sucked, $\bar{U}_{c} / \bar{U}_{m}$ shows two minimum points between $x / D=1$ and 2 . However, downstream of $x / D \geqq 4, \bar{U}_{c} / \bar{U}_{m}$ increases slowly showing almost the same value for all M's, Downstream of $x / D \geqq$ 6 , no significant difference can be found among the velocity distributions for all M's.

(2) Irrespective of $M$ values, the wall-pressure distributions along the pipe axis show steep drop and rise very near the nozzle. The flow is separated from the wall corner. Recirculation zone seems to exist in the flow where $M \leqq 0.76$. The zone becomes wider with smaller $M$.

(3) Turbulence intensity in each section is stronger with smaller $M$, and damping of turbulence delays toward downstream. In the traditional type main nozzle, only the annular flow is used as a driving fluid, which is discharged intermittently and its velocity is as high as subsonic or supersonic. In this report with $R e \fallingdotseq 1.7 \times 10^{4}$ and $R=$ 0.343 , the velocity defect along the pipe axis and the turbulence decrease with increasing $M$. The same condition may be achieved with an appropriate $M$ even if $R e$ is high. This is useful for acceleration and flight of weft without damaging the yarn quality.

Those facts described above seem to prove indirectly that the steady acceleration and flight of weft can be achieved by the tandem 2 stage or 3 stage nozzle unit to which air is gushed into the weft-guide pipe positively.

\section{References}

[1] A. Wahhoud ; Melliand Textilber., 64, 257 (1983).

[2] J. Lünenschloss \& A. Wahhoud; Melliand Textilber., 65, 242 (1984).

[3] J. Lünenschloss \& A. Wahhoud ; Melliand Textilber., 65, 447 (1984).

[4] K. Yoshida, F. Suzuki, S. Kawabata \& J. Hasegawa ; J. Text. Mach. Soc., Japan, 44, T32 (1991).

[5] N. Iwaki, T. Kinari \& H. Yamazaki ; J. Text. Mach. Soc., Japan, 41, T145 (1988).

[6] T. Kiwata, A. Okajima \& T. Nagahisa ; Trans. JSME, B, 55, 3666 (1989).

[7] T. Kiwata \& A. Okajima ; Meeting Papers of JSME, No.920-17 (Vol.B), 81 (1992).

[8] M. Ishida \& A. Okajima ; J. Text. Mach. Soc., Japan, 44, T69 (1991).

[9] K. Teraguchi ; Sen-i Gakkaishi, 48, 116 (1992).

[10] N. Rajaratnum, "Turbulent Jets", p.143, Morikita Press (1981).

[11] M. Barchilon \& R. Curtet ; Trans. ASME, J. Basic. Eng., 86, 777 (1964).

[12] Y. Aoyama, K. Hijikata \& K. Futagami ; Trans. JSME, B, 55, 2212 (1989). 